\title{
Co-OP STUdENT INVOLVEMENT IN THE ADVANCEMENT OF A FACUlTY'S SAFETy EdUCATION AND CULTURE: A LARGE- SCALE Project OF VIDEO CREATION FOR LABORATORY COURSES
}

\author{
A.M. Parker, N. Dyck, R. S. Fuhrer, J. P. Carey \\ Faculty of Engineering, University of Alberta, Edmonton, Alberta \\ aparker@ualberta.ca,jpcarey@ualberta.ca
}

\begin{abstract}
Safety is one of many imperatives considered by engineers as they design, build, test, and maintain solutions to meet client needs. The mindset and relevant knowledge of individual engineers toward safety is formed in the tertiary classroom, which students then carry with them into their careers and influence the safety culture of their workspaces.

As an innovative means to include safety content in the University of Alberta's Faculty of Engineering undergraduate programs, a large-scale project tasked coop students with creating videos promoting and instructing on safety concepts and procedures in laboratory spaces. Beyond the deliverables, this authentic, active learning experience increased the safety knowledge and commitment of both students and staff, infiltrating and positively impacting the safety culture within all engineering and science programs.
\end{abstract}

Keywords: Safety education, project based learning, authentic assessment, video production.

\section{INTRODUCTION}

Safety is of paramount importance in the engineering profession [7]. Ensuring safety and mitigating risk to people, property, and the environment is a critical role of every engineer, be it through basic analysis, planning, standardization, or leadership [3, 7]. Creating a culture of safety in an organization plays a vital role in mitigating and minimizing incidents [9, 15]. Safety management is a social phenomenon, and its success depends on the knowledge and commitment of employees [15]. The same pertains to a higher education institution where professional programs, such as engineering, should be leaders on how to establish and sustain a favourable safety culture in day-to-day teaching and learning. The Canadian Engineering Accreditation Board (CEAB) requires that institutions incorporate safety education into their engineering programs [4]. This includes, but is not limited to, safety in teaching and research laboratories, safety training and procedures, assessments, and safety monitoring. Supporting such a culture presents barriers, and resistance from students and staff can take hold without proper direction, management, and resources from leadership.

The Faculty of Engineering at the University of Alberta recently implemented an initiative that had a positive impact on its safety culture for both students and staff. As an innovative means to include safety content in undergraduate programs, a large-scale project tasked co-op students with creating videos promoting and instructing on safety concepts and procedures in laboratory spaces. The central objective of this project was to gain buy-in from students, increasing their knowledge of, and commitment to, safe workspaces as they created quality, targeted resources for use in engineering and science courses. The project experience was found to positively impress upon the safety mindset of contributing staff as well.

The purpose of this paper is three-fold: First, to share the details of the project so that it may be considered, replicated, or adapted by similar programs elsewhere; second, to highlight its attributes as an authentic, active learning experience; and finally, to connect the project's outcomes to the safety culture within our institution and, ultimately, the profession as engineering graduates enter the workforce.

\subsection{Literature Review}

Safety is one of many imperatives considered by engineers as they design, build, test, and maintain solutions to meet client needs [14]. Three overarching reasons for safety are: (1) humanitarianism (the value of human life); (2) law (to protect the welfare of individuals, property, and the environment); and (3) cost (economic implications of injury, death, or property or environmental damage) [3 (pp. 4-5)]. Engineers are accountable to expectations of conduct and ethics set by licensing associations, corporate social 
responsibility set by companies, as well as laws, regulations, and standards set by governments [3 (pp. 4-5)].

A reflection of its importance, the term safety is ubiquitous in the engineering literature. Whether in reference to areas of practice (e.g. system safety), job titles (e.g. safety professional), or simply as a concept (e.g. workplace safety), a core definition is of safety is "...the state of being relatively free from harm, danger, injury or damage" $[3$ (p. 23)]. Key in this definition is relatively, because it is not possible to remove all risks. Therefore, engineers must determine what is acceptably safe and make decisions accordingly [3 (p. 32)]. Whether it be an outright disregard for one's professional responsibilities or only an unintended mistake, lack of safety can have severe consequences on property, the environment, and human life [12].

Safety culture is the collective values, attitudes, competencies, and commitment to the health and safety programs within an organization $[9,15]$. The mindset and relevant knowledge of individual engineers toward safety is formed in the tertiary classroom, which they subsequently carry with them into their careers $[1,9,11$, 17]. This includes laboratory safety eventually leading to workplace safety, but also risk management concepts in design and processes [5].

In Canada, safety education is embedded in accreditation criteria set forth by the CEAB [4]. It is mentioned in four of the twelve graduate attributes (section 3.1-Design, Professionalism, Impact of engineering on society and the environment, and Ethics and equity) [4]. Laboratory safety is listed as a minimum curriculum component (section 3.4.2), and the topic of health \& safety is included in the list of topics for complementary studies (section 3.4.5) [4]. Accreditation criteria aside, the impetus for including safety in the curriculum is that it makes good pedagogical and societal sense, considering the future responsibilities of graduates in their professional lives [10, 16].

Beyond the general mention of safety by the CEAB, no advice or blueprint is provided for learning activities or assessments [10]. Because of this, faculties of Engineering across the country take varied approaches to engaging students with safety content [12]. Overall, integration of safety throughout a program is preferred over standalone courses in order to convey the message that safety is not an add-on, but rather woven into the fabric of engineering [9]. The lack of prescription for safety education by the CEAB enables curricular innovation, specifically, activities and assessments that have students authentically thinking, problem solving, and acting in the same way as engineers do in the field $[6,13]$. Since engineers encounter real-world problems with technological and social imperatives, higher cognitive activities through active learning are necessary in tertiary education [8].

\subsection{Methodology}

During the Winter, Summer, and Fall terms of 2019, students enrolled in WKEXP 90X (a co-op work experience where $\mathrm{X}$ can be 1 to 6 , depending on the term) created sets of videos for laboratory courses in the Faculty of Engineering and Faculty of Science at the University of Alberta. Selected courses had an identified need for such a resource (i.e. spaces with undergraduate students actively participating in experiments and/or exposed to potential safety hazards) and also had course personnel (instructors and technicians) who were interested and willing to work with students on a project of this size and nature.

Students were grouped into four teams, organized by the disciplines for which they created videos. Team formation was accomplished by self-selection; however, care was taken to ensure that students worked on videos outside their discipline of study. The teams were as follows:

- CEE (Civil and Environmental Engineering, Mining and Petroleum Engineering)

- CME (Chemical and Materials Engineering)

- ECE (Electrical and Computer Engineering)

- MECE (Mechanical Engineering)

One project supervisor was responsible for overseeing all four teams. Each team created a cloud-based shared spreadsheet to overview and track their courses, contact persons, and other project management details for their videos. Teams created a file management system within a shared folder that included all documents and media of the processes and products. Students were provided with all necessary camera equipment and editing software.

Student teams communicated with course personnel and gathered existing laboratory manuals. They pinpointed safety equipment, hazards, and practices, as well as ways to prevent damage to sensitive equipment. Experimentspecific hazards could be identified in the videos, but, as it was stressed throughout the project, students exercised care not to extend the scope to specific experimental procedures.

Storyboards outlined the identified safety issues and determined a cohesive structure for the set of videos of each course. For example, the video set could be organized by hazard, by equipment, or by practice. The storyboards included narration scripts, intended video footage, and text overlays and other visuals. They were peer reviewed by other student teams, as well as by course personnel, and any requested changes were made.

Video recording and editing was an iterative exercise between student teams and course personnel that followed best practices in video production. Course personnel were often on hand for assistance when students were filming in laboratory spaces. Students were encouraged to record multiple takes, angles, and lengths for all shots, for reasons of easier editing and reduced need for reshoots. 
Undergraduate students served as actors in the videos, as they were representatives of the intended audience.

Video drafts were presented at meetings with the project supervisor and other teams. Feedback addressed narration audio, video footage, text overlays and other visuals, transitions, pacing, and overall video structure, accuracy, and quality. Several drafts eventually resulted in a final version of each video. At this time, student teams also drafted and submitted a set of test questions that aligned with each video's content. Subject to internal and external review, these questions were to be incorporated into the question banks of the respective course sites on the University’s learning management system.

\section{RESULTS}

Over the Winter, Summer, and Fall 2019 terms, co-op students enrolled in WKEXP 90X created approximately 105 videos for 52 courses. All videos were less than five minutes in length. Up to seven videos were created per course, and some videos applied to more than one course. The number of courses and videos per course varied due to course needs and video content and complexity. Table 1 summarizes the work completed by each student team.

Table 1: Summary of work completed by each student team in the 2019 WKEXP 90X video creation project.

\begin{tabular}{|c|c|c|}
\hline Team & $\begin{array}{c}\text { Number of } \\
\text { Courses }\end{array}$ & $\begin{array}{c}\text { Number of } \\
\text { Videos Created }\end{array}$ \\
\hline CEE & 15 & 48 \\
\hline CME & 11 & 13 \\
\hline ECE & 16 & 24 \\
\hline MECE & 10 & 20 \\
\hline Total & $\mathbf{5 2}$ & $\mathbf{1 0 5}$ \\
\hline
\end{tabular}

As students were examining existing laboratory manuals and other resources, and even while filming, errors and potential safety hazards were uncovered. For example, one Environmental Engineering lab asked students to collect samples from a sedimentation column. To do this, students had to climb up, stand, and climb down from stools and lab benches (see Figure 1). Once this safety hazard was identified, a solution was quickly found and implemented, which was to bring in some CSA-certified portable platform ladders.

\section{DISCUSSION}

On the premise that safety knowledge and mindset begin in the classroom and follows prospective engineers into their careers, the WKEXP 90X video project is an example of curricular excellence in an undergraduate engineering program. By authoring safety videos (rather than simply viewing them), student teams engaged more deeply and authentically with the content. Project deliverables and intangibles have positively contributed to the safety culture within the faculties of Engineering and Science.

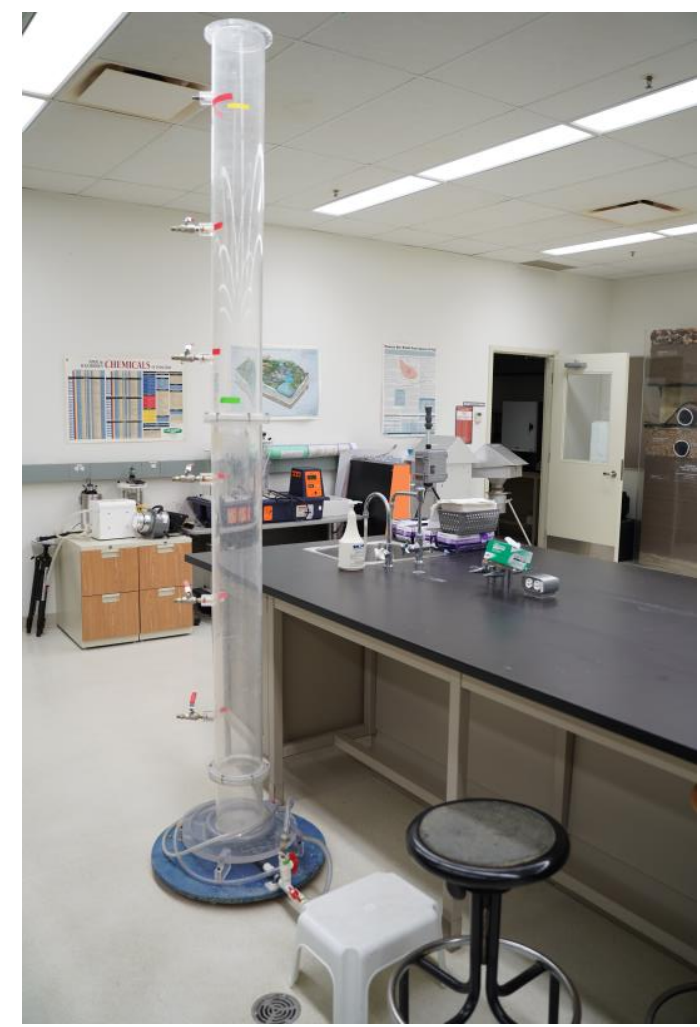

Fig. 1. A safety hazard that, once identified, was quickly resolved.

\subsection{Authenticity of the Project}

Co-op students in WKEXP 90X were "hired" by the Faculty of Engineering at the University of Alberta to create learning and assessment resources for engineering and science courses. Students did not simply read about laboratory safety concepts and procedures in a textbook, hear about them in a lecture, or show their understanding by filling in a bubble sheet. Rather, like any engineer in the field, they had to engage in higher cognitive activities of analyzing and evaluating information in order to design and build a product suitable for their client's needs [2]. Professional and technical skills inherent to the project included:

- Researching

- Thinking

- Designing

- Managing

- Collaborating

- Building

- Communicating

- Reflecting 


\section{- Problem solving}

3.1.1. Researching, Thinking, Designing. Student teams read through related laboratory materials, such as student manuals, standard operating procedures (SOPs), and personal protective equipment (PPE) requirements. They met with course personnel to gain an understanding of course-specific needs. They learned how to safely conduct experiments and use hazardous equipment that were outside their discipline of study, and they were required to have actors accurately portray these in the videos. In one instance, a dangerous error was identified in current safety procedures, and necessary changes were made. Information was integrated into the development of video storyboards, wherein narration script, intended video footage, and text overlays and visuals were to be accurate and concise.

3.1.2. Managing, Collaborating, Building. Student teams had to arrange and attend regular meetings with their project supervisor, course personnel, and other student teams. They had to set and complete weekly goals and were accountable for deadlines. They created a tracking spreadsheet and file management system and developed other project management processes. Tasks were delegated amongst team members, but overall responsibility for the quality of the project was held by all. For this project, students were both the designers (video storyboards) and builders (video filming and editing).

3.1.3. Communicating, Reflecting, Problem Solving. The iterative nature of this project was due to ongoing communication with course personnel about the audio and visual content of the videos. This also required reflection and decision-making for how best to incorporate ideas and feedback into the video development. Errors were encountered and resolved. For example, a segment on having good posture while working at a computer station was inserted into the wrong video. In another case, student actors used the wrong technique to safely take off gloves, which required re-filming. Every stage of the project required commitment and perseverance.

\subsection{Impact of the Project on Safety Culture}

Beyond the teaching and learning of content, a more holistic and intangible outcome of the project has been on the safety culture in the faculties of Engineering and Science. Students of WKEXP 90X, as well as contributing course personnel, reported an increased awareness and commitment toward safe workspaces and an inclination to share this with others. Now as ambassadors of a healthy and progressive safety culture, they are able to influence the safety values, attitudes, competencies, and commitment of those around them $[9,15]$. Additionally, more than 4500 engineering and science students will be impressed upon not only by the content, but by the undergraduate student actors in the videos. The actors are peers who serve as role models, exemplifying the occupational and social importance of safe behaviour.

The ambassadorship of WKEXP 90X students will likely continue for the time remaining in their academic program and will then follow them into their future workspaces. Just as safety culture is woven into the fabric of the engineering profession, the WKEXP 90X deliverables and intangibles - aimed to increase the safety knowledge and commitment of students and staff-have been found to infiltrate and positively impact safety culture of the numerous engineering and science programs at the University of Alberta.

\section{CONCLUSION}

Safety education and culture begins in the classroom and follows engineering students into their careers $[1,9$, $11,17]$, which ultimately impacts the wellbeing of people, property, and the environment [3]. The absence of prescribed learning activities or assessments of safety education by the CEAB makes way for curricular innovation. An authentic, large-scale project at the University of Alberta Faculty had engineering co-op students creating safety videos for laboratory courses in the faculties of Engineering and Science.

Student teams worked outside their discipline of study on such tasks as: development of project management documents and processes; learning to use video equipment and editing software; implementing good practices in video creation; and seeking and incorporating feedback in an effort to build a product to meet client needs. Authoring videos, rather than simply viewing them, had students engaging more deeply and authentically with safety content. Many professional and technical skills were gained by students as they persevered through each iterative stage of the project, such as researching, designing, building, communicating, collaborating, problem solving, reflecting, and more.

Students who have completed WKEXP 90X, as well as course personnel involved in the project, have gained necessary experience, insight, and skills in order to become ambassadors of a healthy and progressive safety culture, for the benefit of all students and staff within engineering and science programs at the University of Alberta.

\section{Acknowledgements}

The authors wish to thank the Office of the Provost and Vice-President (Academic) at the University of Alberta for providing funding for this project.

\section{References}

[1] Hannan Altabbakh, Mohammad A. AlKazimi, Susan Murray, and Katie Grantham, "Safety awareness: Identifying a need for undergraduate engineering students," Professional Safety, pp. 38-41, August 2015. 
Available as of January 18, 2020, from https://www.semanticscholar.org/paper/SafetyAwareness\%3A-Identifying-a-Need-for-StudentsAltabbakhAlKazimi/f90fdde7a79e0a9f6c3f291175bc5582e1977 $\underline{69 d}$

[2] Lorin W. Anderson and David R. Krathwohl, A Taxonomy for Learning, Teaching, and Assessing: A Revision of Bloom's Taxonomy of Educational Objectives. New York: Longman, 2001, 352 pp. \{ISBN: 0321084055\}

[3] Roger L. Brauer, Safety and Health for Engineers. Hoboken, NJ: Wiley, 2016 (3rd ed.), 600 pp. \{ISBN: 9781118959459\}

[4] Canadian Engineering Accreditation Board (CEAB), 2018 Accreditation Criteria and Procedures. Ottawa, ON: Engineers Canada, 2018, 123 pp. Available as of January 18, 2020, from https://engineerscanada.ca/sites/default/files/accreditat ion-criteria-procedures-2018.pdf

[5] Jeffrey S. Castrucci and Graeme W. Norval, "Inculcating safety management through an electronic learning module," in Proc. CEEA Canadian Engineering Conf., CEEA16, (Halifax, NS; 19-22June 2016), 5 pp., 2016.

[6] Centre for Teaching and Learning, "Teaching and learning in higher education: Designing authentic assessments," n.d. Available as of January 18, 2020, from

http://www.queensu.ca/teachingandlearning/modules/a ssessments/20_s2_12_designing_authentic_assessmen $\underline{\text { ts.html }}$

[7] Engineers Canada, "Public guideline: Risk management," August 2012. Available as of January 18, 2020, from https://engineerscanada.ca/publications/publicguideline-risk-management

[8] Sanjay Goel and Nalin Sharda, "What do engineers want? Examining engineering education through Bloom's taxonomy," in 15th Annual Conference for the Australasian Association for Engineering Education, AAEE2004, (Toowoomba, QLD; 27-29September 2004), 14 pp., 2004.

[9] Dennis C. Hendershot and Wendy Smades, "Safety culture begins in the classroom," Process Safety Progress, vol. 26, no. 2, pp. 83-84, 2007. Available as of January 18, 2020, from https://doi.org/10.1002/prs.10200

[10] G. S. Langdon, K. Balchin, and P. Mufamadi, "Evaluating risk awareness in undergraduate students studying mechanical engineering," European Journal of Engineering Education, vol. 35, no. 5, pp. 553-562, 2010. Available as of January 18, 2020, from https://doi.org/10.1080/03043797.2010.489939

[11] Effiong Mkpat, Genserik Reniers, and Valerio Cozzani, "Process safety education: A literature review," Journal of Loss Prevention in the Process Industries, vol. 54, pp. 18-27, 2018. Available as of January 18, 2020, from https://doi.org/10.1016/j.jlp.2018.02.003

[12] G. W. Norval, "Introduction to health and safety responsibilities," in Proc. CEEA Canadian Engineering Education Conf., CEEA14, (Canmore, AB; 8-11June 2014), 4 pp., 2014.

[13] Stuart Palmer, "Authenticity in assessment: Reflecting undergraduate study and professional practice," European Journal of Engineering Education, vol. 29, no. 2, pp. 193-202, 2004. Available as of January 18, 2020 , from https://doi.org/10.1080/03043790310001633179

[14] Honor J. Passow and Christian H. Passow, "What competencies should undergraduate engineering programs emphasize? A systematic review," Journal of Engineering Education, vol. 106, no. 3, pp. 475-526, 2017. Available as of January 18, 2020, from https://doi.org/10.1002/jee.20171

[15] Rafiq M. Choudhry, Dong Ping Fang, and Sherif Mohamed, "The nature of safety culture: A survey of the state of the art," Science Direct, vol. 45, no. 10, pp. 993-1012, 2007. Available as of January 24, 2020, from https://doi.org/10.1016/j.ssci.2006.09.003

[16] Graham Schleyer, Rui Fang Duan, Julian Williamson, and Nicola Stacey, "Assessing the awareness of risk concepts by new engineering students," International Journal of Mechanical Engineering Education, vol. 35, no. 3, pp. 184-197, 2007. Available as of January 18, 2020, from https://doi.org/10.7227/IJMEE.35.3.3

[17] Anrong Zeng and Anran Zeng, "Cultivating a safety mindset in chemical engineering students: Design of a training module," Education for Chemical Engineers, vol. 20, pp. 32-40, 2017. Available as of January 18, 2020, from https://doi.org/10.1016/j.ece.2017.07.004 